
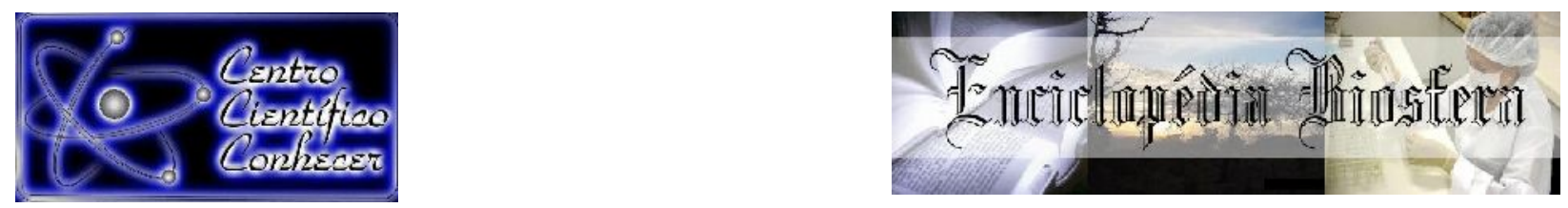

\title{
CONSERVAÇÃO DE ESTRADAS NÃO PAVIMENTADAS POR MEIO DE MODELO GEOLOCALIZADO
}

\author{
Alisson Neves Harmyans Moreira ${ }^{1}$, Nori Paulo Griebeler $^{2}$, Rherison Tyrone Silva \\ Almeida $^{3}$, Simone Gonçalves Sales Assunção ${ }^{4}$ \\ 1 Professor Adjunto da Escola de Agronomia da Universidade Federal de Goiás \\ (alissonharmyans@gmail.com) Goiânia-Brasil \\ 2 Professor Associado da Escola de Agronomia da Universidade Federal de Goiás \\ 3 Professor Assistente da Escola de Agronomia da Universidade Federal de Goiás \\ 4 Professora Adjunta da Escola de Agronomia da Universidade Federal de Goiás \\ Recebido em: 04/10/2019 - Aprovado em: 30/11/2019 - Publicado em: 15/12/2019 \\ DOI: 10.18677/EnciBio_2019B13
}

\begin{abstract}
RESUMO
As estradas não pavimentadas têm papel socioeconômico assegurando o transporte de produtos e a mobilidade de pessoas. Dessa forma, adequações das redes viárias são necessárias com o intuito de evitarem o escoamento superficial a fim de que não se transformem em canais e, por conseguinte, a formação de processos erosivos. Dados de campo, informações geomorfológicas e geotecnologias como Sistema de Informação Geográfica (SIG) são variáveis fundamentais para o planejamento, recomendação e a quantificação dos dispositivos de drenagem. Nesse sentido, para a sub-bacia do córrego Olaria, os resultados apresentaram que a sub-bacia tem 50,1 $\mathrm{km}$ de rede viária, dos quais apenas $12,1 \%$ não precisaram de lombadas com saídas d'água. No total, recomendaram-se 953 lombadas com saídas d'água e 83 dissipadores de energia em canais de drenagem evidenciando que o traçado geométrico, o relevo e os solos foram desconsiderados nas locações das estradas não pavimentadas.
\end{abstract}

PALAVRAS-CHAVE: Dispositivos de drenagem, estradas não pavimentadas, planejamento.

\section{CONSERVATION OF UNPAVED ROADS FOR THE GEOLECATED MODEL}

\begin{abstract}
Unpaved roads play a socio-economic role in ensuring product transportation and people mobility. Thus, adjustments of road networks are necessary in order to avoid runoff so that they do not turn into channels and, consequently, the formation of erosive processes. Field data, geomorphological information and geotechnologies such as Geographic Information System (GIS) are fundamental variables for the planning, recommendation and quantification of drainage devices. In this sense, for the Olaria stream sub-basin, the results showed that the sub-basin has $50.1 \mathrm{~km}$ of road network, of which only $12.1 \%$ did not need spines with water outlets. In all, 953 speed bumps with water outlets and 83 energy dissipators in drainage channels were recommended, evidencing that the geometric layout, relief and soils were disregarded in unpaved road locations.
\end{abstract}

KEYWORDS: Dranaige devices, unpaved roads, planning. 


\section{INTRODUÇÃO}

A malha rodoviária brasileira possui extensão de aproximadamente 1,7 milhões de quilômetros, sendo 12,4 \% de estradas pavimentadas (CNT, 2018). Esse expressivo número de rede viária sem pavimentação é utilizada para o transporte de pessoas aos centros urbanos e produtos, principalmente agropecuários.

As estradas não pavimentadas têm sido associadas a um número de efeitos sobre os processos hidrológicos e geomorfológicos em escala de bacias hidrográficas, tais como o aumento das taxas de erosão da superfície. Para Enriquez et al. (2015), as estradas não pavimentadas são uma das principais fontes de produção de sedimentos e influenciam nos processos hidrológicos de diversas formas. Em comparação com as áreas agrícolas, superfícies compactadas de estradas podem aumentar a geração de escoamento superficial por meio da diminuição da capacidade de infiltração do solo aumentando a produção de sedimentos sobre o tráfego pesado. Por isso, em uma sub-bacia agrícola, as perdas de solo em estradas são diferentes do que em áreas agrícolas (CAO et al., 2014).

A partir destas variáveis torna-se possível detectar as áreas com maior ou menor suscetibilidade a erosão hídrica, e com isto, determinar possíveis locais para a implantação de dispositivos que reduzam este efeito, como as lombadas com saídas d'água e dissipadores de energia (BAESSO; GONÇALVES, 2003). Para esses autores, as lombadas são elevações construídas transversalmente ao longo de toda a largura da plataforma da estrada. O objetivo desse dispositivo de drenagem é transportar as águas superficiais provenientes dos canais de drenagem de um lado para o outro das estradas, direcionando-as aos dispositivos adequados. Os dissipadores de energia são dispositivos (materiais estáveis originários de rochas sãs) utilizados nos canais de drenagem e/ou nas saídas oriundas destes canais, com a finalidade de reduzir a energia potencial no escoamento das águas superficiais.

A rigor, grande parte das estradas não pavimentadas é construída sem planejamento sendo, historicamente, condicionadas ao aproveitamento de caminhos ou trilhas existentes. Portanto, há a necessidade de estudos detalhados das áreas em que serão instaladas as vias, bem como, de suas adaptações para melhor conservá-las, acarretando em menores impactos ambientais e menores custos econômicos para esta prática (SCHARRÓN; LAFEVOR, 2018).

A conectividade hidrológica relacionada às estradas tem recebido considerável atenção nos últimos anos por meio de estudos de campo, Sensoriamento Remoto e/ou baseados em Sistema de Informação Geográfica (SIG) (WEMPLE et al., 2017). Nesse contexto, o SIG é uma importante ferramenta de análise e tomada de decisões no planejamento da rede viária e na acessibilidade em ambiente rural (SAKAMOTO; LIMA, 2016).

Nesse sentido, o uso de técnicas de Geoprocessamento, sobretudo o uso desse sistema, possibilita uma visão ampla da área de interesse e a possibilidade de modelagem de diferentes bases de dados. Assim, com o auxílio de um SIG no planejamento da rede viária, este trabalho teve como objetivo recomendar e quantificar os dispositivos de drenagem no município de Terezópolis de Goiás.

\section{Àrea de estudo}

\section{MATERIAL E MÉTODOS}

O trabalho foi desenvolvido no interstício de outubro à dezembro de 2017 na sub-bacia do córrego Olaria, no município de Terezópolis de Goiás, localizada 
geograficamente entre as coordenadas, latitudes ( $16^{\circ} 25^{\prime} 24^{\prime \prime} \mathrm{S}$ e $16^{\circ} 25^{\prime} 55^{\prime \prime} \mathrm{S}$ ) e longitudes (49 $03^{\prime} 57^{\prime \prime} \mathrm{W}$ e $\left.49^{\circ} 05^{\prime} 40^{\prime \prime}\right) \mathrm{W}$ (Figura 1). De acordo com o IBGE (2019), o município possui área de $106,913 \mathrm{~km}^{2}$ e uma população de 8.043 habitantes, com maioria residente em áreas rurais. A área de estudo compreende a $29,5 \%$ da área municipal e caracteriza-se como a sub-bacia de maior abrangência de Terezopólis de Goiás. A escolha dessa sub-bacia, ocorreu em função de sua relevância ambiental (integrada a área de proteção da bacia hidrográfica do ribeirão João Leite), socioeconômica (grande produção de hortifrúti) e pela facilidade de acesso à capital, que se faz pela BR - 153, a 27 km de Goiânia.

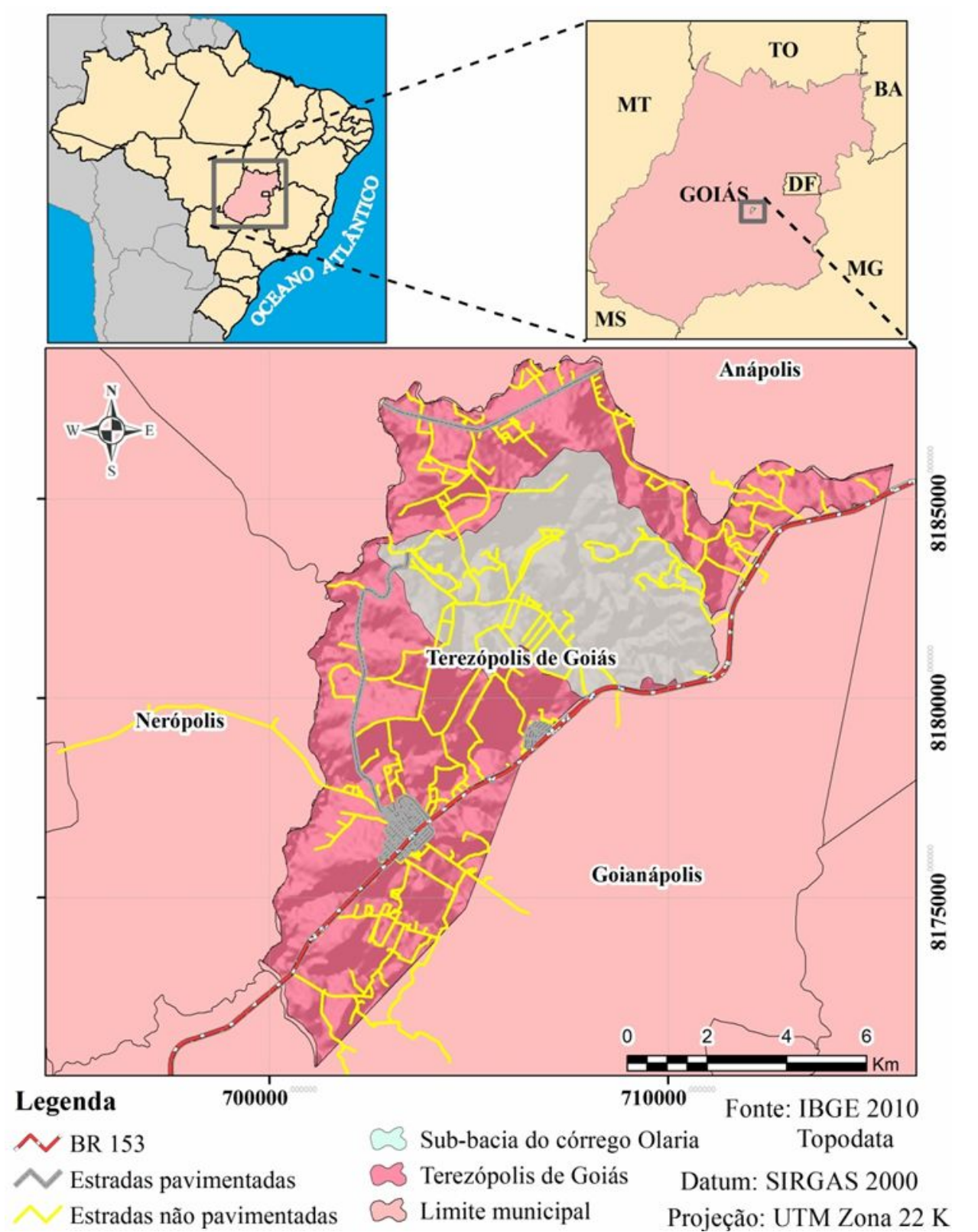

FIGURA 1. Localização da sub-bacia do córrego Olaria no município de Terezópolis de Goiás.

\section{Bases de dados}

As bases de dados pedológicas cedidas pela Secretaria do Meio Ambiente e 
Recursos Hídricos de Goiás (SEMARH) e a pesquisa de campo na rede viária da sub-bacia foram fundamentais para o desenvolvimento do SIG. Nesse sentido, o trabalho foi dividido em duas etapas: estruturação da base de dados e recomendações dos dispositivos de drenagem.

A base de dados digital da rede viária foi construída a partir da vetorização da imagem do sensor Tailandês Thailand Earth Observation Satellite (THEOS) georreferenciada no datum SIRGAS 2000, projetada em Universal Transverse Mercator (UTM) na zona $22 \mathrm{~K}$. A partir deste raster e com auxílio do software ArcGIS® obteve-se a espacialização dos dados com a resolução de $2 \mathrm{~m}$.

Após a vetorização das estradas realizadas a partir da imagem THEOS, criaram-se vários segmentos por meio da ferramenta de topologia do aplicativo. Os dados do projeto Topodata disponibilizados pelo Instituto Nacional de Pesquisas Espaciais (INPE) foram utilizados para a obtenção das informações altimétricas, a partir de um Modelo Digital de Elevação (MDE). A folha usada para classificação foi $15 s 495\left(15^{\circ} 00^{\prime} 00^{\prime \prime} \mathrm{S}\right.$ e $\left.49^{\circ} 30^{\prime} 00^{\prime \prime} \mathrm{W}\right)$, compatíveis com a articulação 1:250.000, entretanto, salienta-se que a utilização dessa imagem de resolução métrica (30 metros) não é a mais adequada para atribuição da declividade, mas devido a carência de dados gratuitos de melhor resolução para o local utilizou-se essa fonte para subsidiar e consolidar esse atributo. Nesse sentido, usando o recurso de interpolação vetorial, extraíram-se para os segmentos, informações como as altitudes mínima, média e máxima; declividade média e distâncias por meio do modelo builder (Figura 2).

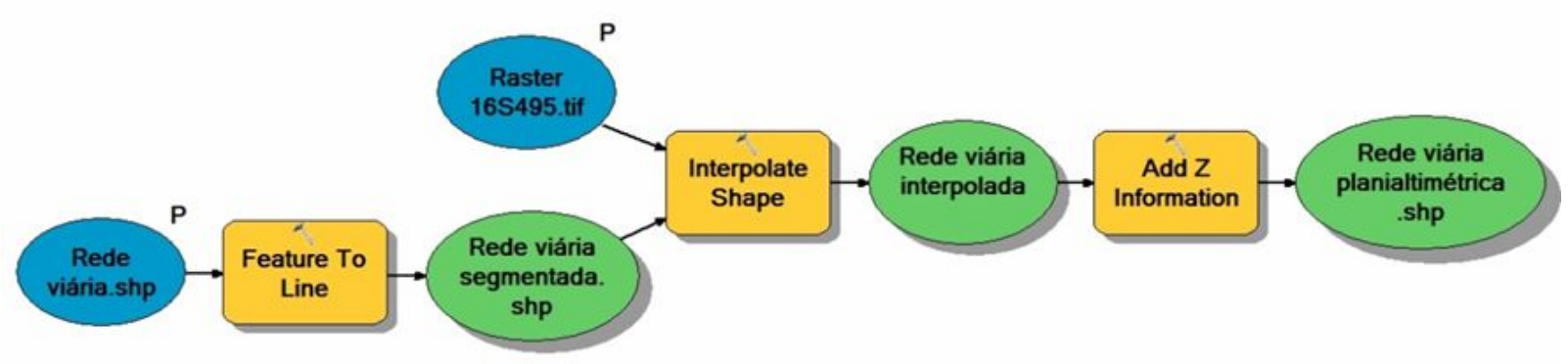

FIGURA 2. Sequência de ferramentas utilizadas para a geração da rede viária com informações planialtimétricas.

Os dados obtidos em campo subsidiaram a classificação das estradas não pavimentadas em relação ao uso de revestimento. Nessa etapa, verificou-se nos trechos, o tipo de revestimento do leito. Proposto por Baesso e Gonçalves (2003), essas estradas são divididas em três níveis:

- Nível 1 - estradas não pavimentadas sem revestimento, com apenas o leito natural;

- Nível 2 - estradas não pavimentadas parcialmente revestidas;

- Nível 3 - estradas não pavimentadas adequadas. Apresentam revestimento primário em toda sua extensão.

Para recomendação dos dispositivos de drenagem, além do uso de dados planialtimétricos, utilizou-se o mapa de erodibilidade dos solos proposto por Oliveira 
(1996) e adaptado conforme Salomão (1999). As classes de erodibilidade estão descritas no Quadro 1.

QUADRO 1. Classes de erodibilidade (E) e índices de erodibilidade relativa (IER) em função do tipo de solo.

\begin{tabular}{|c|c|c|}
\hline $\mathrm{E}$ & IER & Solo \\
\hline $\mathrm{E}_{1}$ & 8,1 a 10,0 & $\begin{array}{c}\text { Neossolo Quartzarênico, Cambissolo, Neossolo Litólico, } \\
\text { Plintossolos e Argissolos de textura arenosa / média } \\
\text { abruptos }\end{array}$ \\
\hline $\mathrm{E}_{2}$ & 6,1 a 8,0 & Latossolo Amarelo, Argissolos de textura média argilosa \\
\hline $\mathrm{E}_{3}$ & 4,1 a 6,0 & $\begin{array}{l}\text { Latossolo Vermelho-Amarelo, Argissolos de texturas } \\
\text { argilosas }\end{array}$ \\
\hline $\mathrm{E}_{4}$ & 2,1 a 4,0 & Latossolo Vermelho e Nitossolo \\
\hline $\mathrm{E}_{5}$ & 0,0 a 2,0 & Gleissolo \\
\hline
\end{tabular}

Fonte: Adaptado de Salomão (1999).

\section{Recomendações dos dispositivos de drenagem}

A distribuição dos espaçamentos das lombadas com saídas d' água foi realizada a partir das declividades médias nos trechos (segmentos), sendo: declividades de $2 \%$ a $5 \%, 50$ m de distância entre os dispositivos de drenagem; de $6 \%$ a 10\%, 40 m; e acima de 10\%, 30 m (MORAES et al., 2004). Esses valores e a base de dados planialtimétrica possibilitaram a elaboração de uma sintaxe computacional para a recomendação das lombadas com saídas d'água.

Os dissipadores de energia nas sarjetas seguiram os critérios de distribuição propostos por Baesso e Gonçalves (2003) (Tabela 1). Para a recomendação desses dispositivos de drenagem na sub-bacia, os atributos de "grupos de solos" e "suscetibilidade à erosão laminar" do Quadro 1 foram correlacionados com as classes de erodibilidade da Tabela 1. Essa correlação pode ser visualizada na Tabela 2.

TABELA 1. Espaçamento dos dissipadores de energia nas sarjetas em função dos grupos de solos, das classes de erodibilidade, do potencial de erosão e da declividade da rampa.

$$
\text { Declividade de rampa (\%) }
$$

\begin{tabular}{cccc}
$\begin{array}{c}\text { Grupo de } \\
\text { Solos }\end{array}$ & $\begin{array}{c}\text { Potencial de } \\
\text { Erosão }\end{array}$ & 10 a 15 & $>15$ \\
\cline { 3 - 4 } & Muito Alta & $\ldots \ldots \ldots \ldots$ Espaçamento $(\mathrm{m}) \ldots \ldots \ldots \ldots$ \\
C & Alta & 10 & 5 \\
B & Moderada & 15 & 10 \\
A & Baixa & 20 & 15 \\
& 25 & 20
\end{tabular}

Fonte: Baesso e Gonçalves (2003). 
TABELA 2. Relação entre o grupo de solos, classes de erodibilidade, suscetibilidade à erosão laminar e recomendação dos dissipadores de energia nas sarjetas.

\begin{tabular}{|c|c|c|c|c|}
\hline \multirow{3}{*}{$\begin{array}{l}\text { Grupo de } \\
\text { Solos }\end{array}$} & \multirow{3}{*}{$\begin{array}{l}\text { Classes de } \\
\text { Erodibilidade }\end{array}$} & \multirow{3}{*}{$\begin{array}{l}\text { Suscetibilidade } \\
\text { à erosão } \\
\text { laminar }\end{array}$} & \multicolumn{2}{|c|}{ Declividade de rampa (\%) } \\
\hline & & & 10 a 15 & $>15$ \\
\hline & & & \multicolumn{2}{|c|}{$\ldots \ldots \ldots . .$. Espaçamento $(m) \ldots \ldots \ldots . .}$. \\
\hline $\mathrm{D}$ & $E_{1}$ & Muito Alta & 10 & 5 \\
\hline C & $E_{2}$ & Alta & 15 & 10 \\
\hline B & $E_{3}$ & Moderada & 20 & 15 \\
\hline A & $E_{4}$ e $E_{5}$ & Baixa & 25 & 20 \\
\hline
\end{tabular}

Fonte: Adaptado de Baesso e Gonçalves (2003) e Salomão (1999).

Para a relação entre o grupo de solos, classes de erodibilidade, suscetibilidade à erosão laminar e recomendação dos dissipadores de energia nas sarjetas (Tabela 2), elaborou-se sintaxe booleana.

\section{RESULTADOS E DISCUSSÃO}

Com a vetorização da rede viária, verificou-se que a sub-bacia do Córrego Olaria possui $50,9 \mathrm{~km}$ de estradas, sendo $50,1 \mathrm{~km}$ ou $98,3 \%$ desse total caracterizadas pelas estradas não pavimentadas (Figura 3 ). Esse índice equivale a 172 segmentos, dos quais 37 não necessitaram de lombadas com saídas d'água. Esses segmentos que não necessitam de intervenção desse dispositivo de drenagem representam apenas $12,1 \%$. No total, foram recomendadas 953 lombadas com saídas d'água. Tal fato sinaliza que o relevo é um critério ignorado em relação as estradas não pavimentadas.

Para dois segmentos, indicaram-se espaçamentos de $30 \mathrm{~m}$ em $30 \mathrm{~m}$. Nesses segmentos foram encontradas inclinações médias de rampas superiores a $10 \%$. A rampa mais íngreme da sub-bacia do Córrego Olaria apresentou declividade média de $11 \%$, com desnível de $100 \mathrm{~m}$ e comprimento de rampa com aproximadamente $980 \mathrm{~m}$, recomendaram-se 32 lombadas com saídas d'água. Desse modo, esse segmento apresentou a maior quantidade de lombadas com descidas d'água devido as suas características geométricas. Por não seguir um rigor geométrico, a construção de estradas rurais com este perfil deve ser evitada.

As recomendações de lombadas a partir da inclinação da rampa no Brasil são embasadas ao manual de melhores práticas conservacionistas relacionadas as estradas não pavimentadas desenvolvidos pela U.S Environmental Protection Agency (US EPA, 2001).

Esses segmentos com elevada declividade podem ser considerados críticos quando se tem grandes comprimentos de rampas, pois aumentam a energia cinética da água sobre as vias, e se a drenagem for precária ou ausente, essas estradas se transformam em canais preferenciais para o escoamento da água, tornando possível o surgimento de sulcos erosivos. O número de lombadas com saídas d'água espaçadas de $40 \mathrm{~m}$ em $40 \mathrm{~m}$ e $50 \mathrm{~m}$ em $50 \mathrm{~m}$ foram de 289 e 625, respectivamente. Isso representa $85,5 \%$ do quantitativo de dispositivos de drenagem recomendados.

$\mathrm{Na}$ Figura 3, nota-se que os segmentos com recomendações de $40 \mathrm{~m}$ em 40 $\mathrm{m}$, em sua maioria, cortaram perpendicularmente as curvas em nível. Como as estradas rurais são construídas no próprio terreno natural (ausência de projetos), essa condição geométrica pode elevar a declividade média da rampa em encostas mais íngremes. No que concerne as informações pedológicas, observa-se na área 
da sub-bacia (3.152,8 ha), a predominância de 46,2\% Latossolo Vermelho Ácrico $(\mathrm{LVw})$ [1.476,3 ha] e do Argissolo Vermelho Amarelo Eutrófico (PVAe) com $44,3 \%$ ou $1.395,8$ ha (Figura 4).

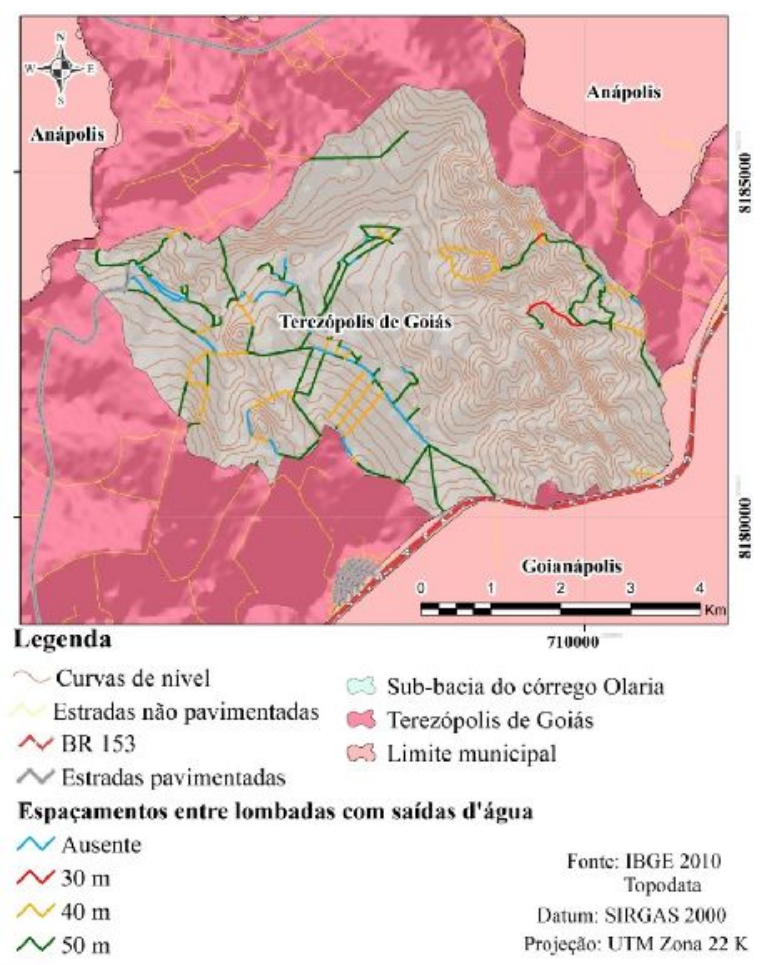

FIGURA 3. Recomendações de espaçamentos das lombadas com saídas d'água para a sub-bacia do córrego Olaria em Terezópolis de Goiás.

Associaram-se quatro classes de erodibilidade do solo (E1, E2, E4 e E5). A classe que ocorreu com maior frequência foi a E4 (aproximadamente $46,8 \%$ da área), classificada com baixa suscetibilidade à erosão laminar (Figura 4). A classe PVAe de alta suscetibilidade à erosão laminar (E2) e o LVw (E4), concentram-se a maior parte da rede viária não pavimentada. Em se tratando dessa classe de Argissolo como leito natural existem dois vieses.

Apesar das classes de solos, bem como seu uso serem importantes em modelos preditivos como a Universal Soil Loss Equation (USLE), Marcelino et al. (2012) propõem que é necessário ter bases de dados confiáveis e reitera a escassez de outras informações para práticas conservacionistas. Nesse sentido, os autores exploram o fator topográfico Length Slope factor (LS) em seu modelo de recomendação de camalhões para estradas florestais devido a facilidade de obtenção e elaboração de dados. Emmert e Pereira (2016) mostram a dificuldade e a onerosidade na obtenção de informações para caracterização geotécnica e classificação de solos para estradas não pavimentadas em seu estudo de caso. Nesse sentido, a recomendação dos dissipadores de energia nesse trabalho foi possível devido a disponibilidade de dados para aquela região cedidas por órgãos governamentais e bases literárias. 


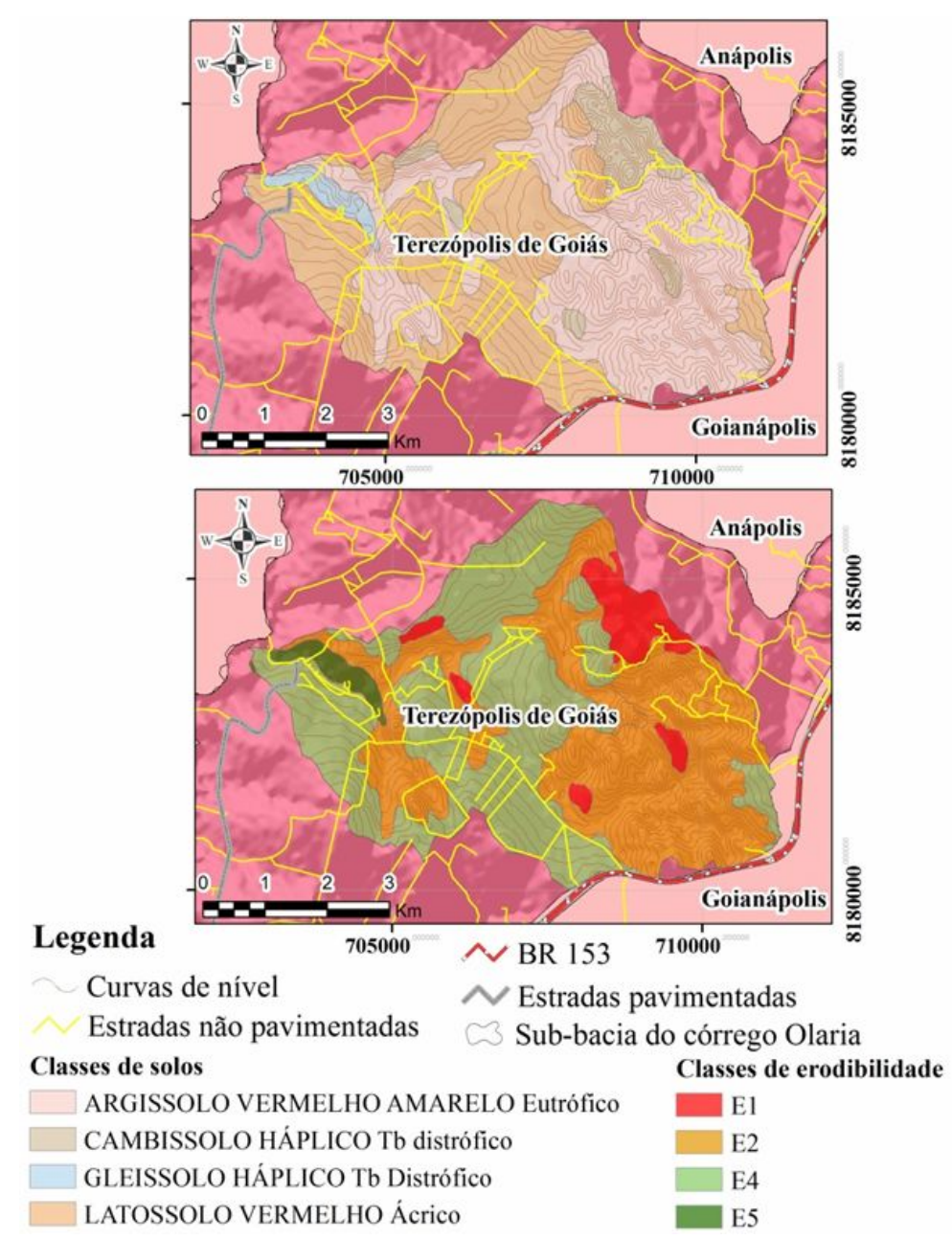

FIGURA 4. Classes de solos e erodibilidade de solos encontradas na sub-bacia do córrego Olaria em Terezópolis de Goiás.

A textura argilosa favorece a compactação do leito, necessitando de menos manutenções em rampas mais planas. Por outro lado, maiores comprimentos de rampa e grandes desníveis são agravantes para a perda de solo. As áreas com erodibilidade E1, classificadas com suscetibilidade à erosão laminar muito alta, encontram-se na região mais ao norte da sub-bacia, entretanto, são menos frequentes. Essas classes atreladas ao tipo de revestimento, a declividade da estrada e o regime de precipitação anual podem aumentar a tensão cisalhante agravando os processos erosivos.

Nesse contexto, na Figura 5 é observado que $85,8 \%$ das estradas não pavimentadas são constituídas apenas do leito natural (nível 1) e 14,2\% são revestidas parcialmente (nível 2). Ainda, ao comparar as observações de campo com a Figura 5, nota-se que as adequações são mais frequentes nas vias principais que cortam perpendicularmente a sub-bacia. No entanto, analisando as Figuras 3, 4 e 5, essas estradas classificadas como nível 2 são as que carecem menos de intervenções em se tratando de elementos pedológicos e de relevo. Nenhum leito estradal caracterizou-se como nível 3. 


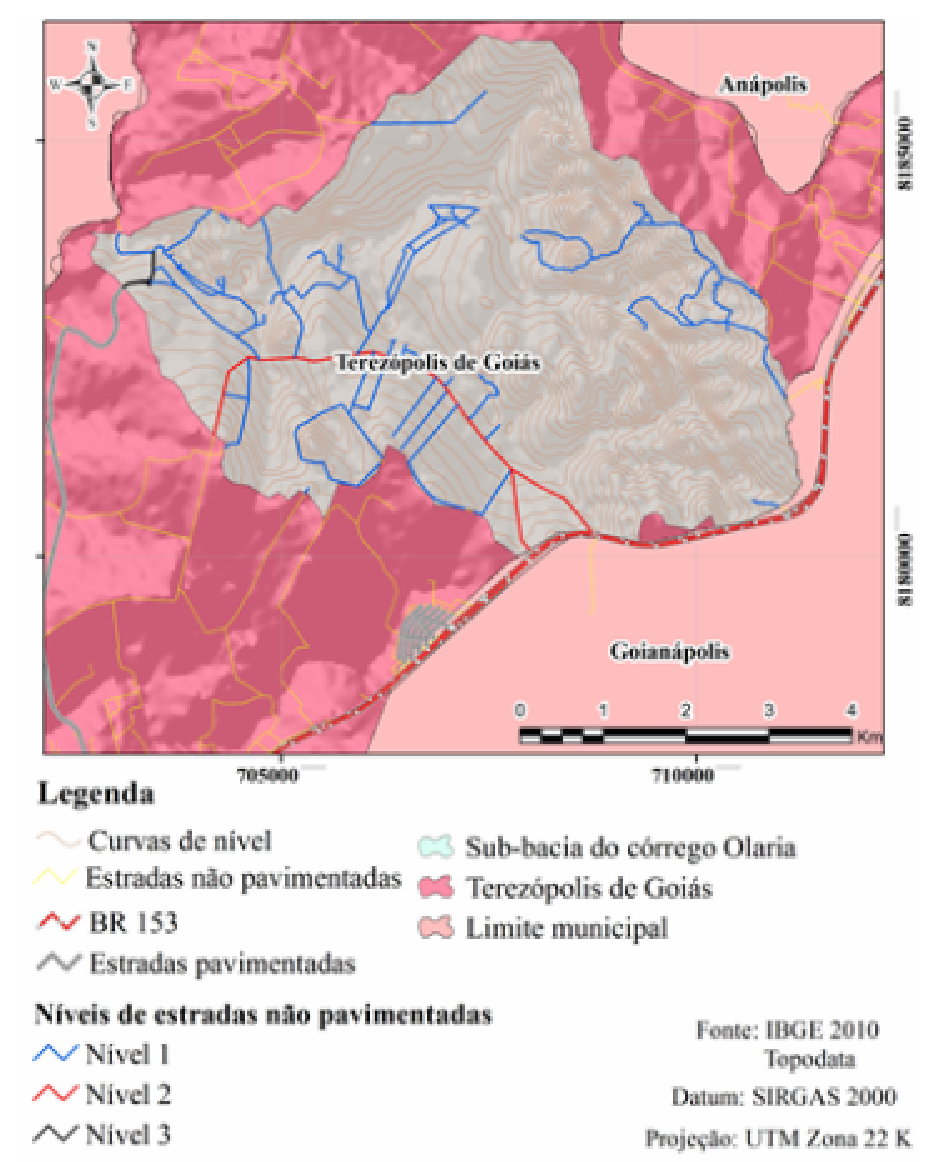

FIGURA 5. Níveis de estradas não pavimentadas encontradas na sub-bacia do córrego Olaria em Terezópolis de Goiás.

$\mathrm{Na}$ Figura 6 são visualizados os segmentos que apresentaram as recomendações de dissipadores de energia. A necessidade desses dispositivos de drenagem ocorreu para apenas dois segmentos. Comparando as Figuras 5 e 6 , observa-se que esses trechos são caracterizados como estradas não pavimentadas de nível 1. Isso implica que os leitos naturais dessas vias são constituídos de solos com classes de suscetibilidade à erosão laminar de alta a muito alta.

Para essas estradas de nível 1, recomendaram-se 19 dissipadores de energia em sarjetas com espaçamentos de $10 \mathrm{~m}$ em $10 \mathrm{~m}$ e 64 dissipadores espaçados de $15 \mathrm{~m}$ em $15 \mathrm{~m}$, totalizando 83 dispositivos. Os dissipadores com espaçamentos de 10 apresentaram declividades médias de $11 \%$ e $10 \%$, respectivamente. Os Cambissolos Háplicos Tb distróficos (CXbd) foi a classe de solo abundante nos segmentos com dissipadores de energia espaçados com $10 \mathrm{~m}$, enquanto nos dispositivos com espaçamento de $15 \mathrm{~m}$, houve a predominância do Argissolo Vermelho Amarelo Eutrófico (Figura 4). Foram quantificados 64 dissipadores com espaçamentos de $15 \mathrm{~m}$ no trecho mais declivoso da sub-bacia. Somando as 32 lombadas com saídas d'água recomendadas anteriormente, apenas nesse segmento foram indicados 96 dispositivos de drenagem.

As condições técnicas dessas requerem maior atenção da gestão pública. Em geral, se as estradas não pavimentadas fossem bem planejadas e adequadas, reduziria a quantidade de dispositivos de drenagem e, consequentemente, diminuiria o custo de implantação e manutenção. Para Weeb et al. (2014), as estradas não 
pavimentadas sem planejamento perdem sua função socioeconômica transformando-se em canais. Nesse sentido, Cao et al. (2014) inferem que a ausência de práticas conservacionistas nas áreas agrícolas e as estradas rurais são as grandes responsáveis pela produção de sedimentos.

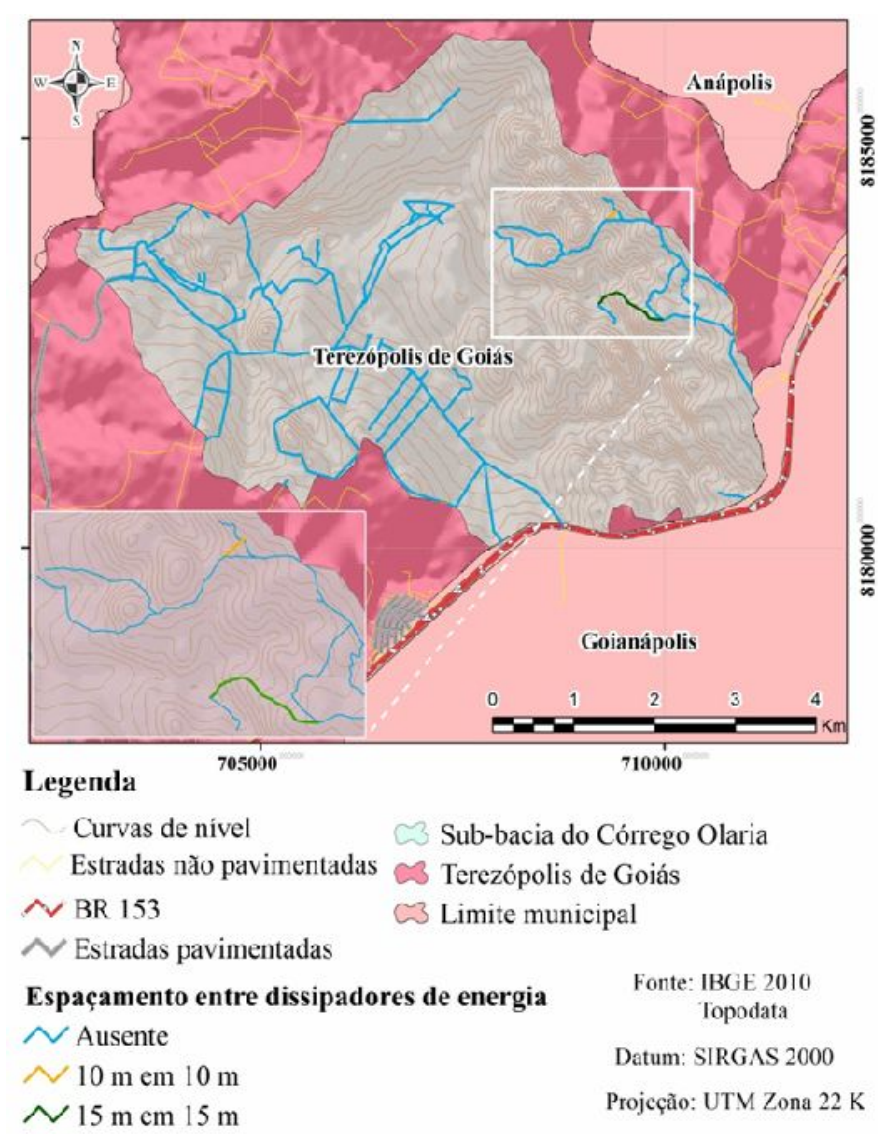

FIGURA 6. Recomendações de espaçamentos dos dissipadores de energia nas sarjetas para a sub-bacia do córrego Olaria em Terezópolis de Goiás.

\section{CONCLUSÕES}

A base de dados planialtimétricas e pedológicas utilizadas no trabalho possibilitaram a elaboração de modelos e sintaxes para as recomendações de lombadas com saídas d'água e dissipadores de energia em sarjetas.

Por meio dos resultados obtidos com o SIG, infere-se que os critérios geomorfológicos foram ignorados na implantação da rede viária na sub-bacia. Tal fato é evidenciado pelos problemas encontrados nos traçados geométricos e o excesso de recomendações desses dispositivos de drenagem. Nesse sentido, sobre o ponto de vista quantitativo, o trabalho indicou à gestão pública, dois trechos considerados críticos requerem maior atenção em relação ao custo de implantação e manutenção dos dispositivos de drenagem.

\section{REFERÊNCIAS}

BAESSO, D. P.; GONÇALVES, F. L. R. Estradas rurais, técnicas adequadas de manutenção. Florianópolis, DER, 2003. 199p. 
CAO, L.; ZHANGI, K.; LIANG, Y. Factors affecting rill erosion of unpaved loess roads in China. Earth Surface Processes and Landforms. Malden, 27 (2014): 12671283.2014.

CNT. Somente $12,4 \%$ da malha viária rodoviária brasileira é pavimentada. Disponível em: <http://cnt.org.br/agencia-cnt/somente-12-da-malha-rodoviariabrasileira-pavimentada> Acesso em: outubro 2018.

EMMERT, F.; PEREIRA, R. S. Caracterização geotécnica e classificação de solos para estradas florestais: estudo de caso. Ciência Florestal, Santa Maria, v.26, n.2, p.601-613, Abr. 2016.

ENRIQUEZ, A. G.; SILVA, D. P.; PRUSKI, F. F.; GRIEBELER, N. P.; CECON, P. R. Erodibilidade e tensão crítica de cisalhamento no canal de drenagem de estrada rural não pavimentada. Revista Brasileira da Engenharia Agrícola e Ambiental, Campina Grande, v.19, n. 2, p. 160-165, Fev/ 2015.

IBGE. Censo demográfico 2019.2 Disponível em:<http://ibge.gov.br/cidadesat/xtras/terezopolis-de-goias> Acesso em: setembro 2019.

MARCELINO, F. A.; FENNER, P. T.; SHACK-KICHNER, H.; ESPERANCINI, M. S. T.; SIMÕES, D. Relação entre risco de erosão e distância de camalhões em estradas florestais. Revista Energ. Agric, v. 27, n.3, p. 61-73, Jul. 2012.

MORAES, O.; MENDES, R. B.; BUBLITZ, U.; BARAS, V.; LOYOLA, G. P. Adequação de estradas rurais integradas aos sistemas conservacionistas. Curitiba, Secretaria de Estado da Agricultura e do Abastecimento, 2004. 74p.

OLIVEIRA, V. A. Levantamento de reconhecimento com alta intensidade dos solos da Bacia do Rio João Leite. Comissão 5. "Gênese, morfologia e classificação do solo", 1996, 1 CD-Rom.

US EPA. Energy and Environmental Affairs. 2001. Disponível em:

http://www.mass.gov/eea/docs/dep/water/resources/a.../dirtroad.doc > Acesso em: janeiro de 2017.

SAKAMOTO, E.; LIMA, J. P. Acessibilidade em ambiente rural: uma abordagem multicritério com uso de SIG. Transportes, v. 24, n.1, p. 63-73, Fev. 2016.

SALOMÃO, F. X. T. Controle e prevenção dos processos erosivos. In: GUERRA, T. A. J.; SILVA, A. S. \& BOTELHO, R.G. (Organizadores). Erosão e Conservação dos solos: conceitos, temas e aplicações. Rio de Janeiro: Bertrand Brasil, 1999, p. 229265.

SCHARRON, C. E.; LAFEVOR, M. C. Effects of Forest Roads on Runoff Initiation in Low-Order Ephemeral Streams. Water Resources Research, v. 54, p. 8613-8631. Set. 2018. 
WEMPLE, B. C.; CLARK, G. E.; ROSS, D. S.; RIZZO, D. M. Identifying the spatial pattern and importance of hydro-geomorphic dranaige impairments on unpaved roads in the northeastern USA. Earth Surface Process and Landforms, v. 42, p. 1652-1665. Jan. 2017.

WEEB, N. P.; HERRICK, J. E.; DUNIWAY, M. C. Ecological site-based assessments of wind and water erosion: informing accelerated soil erosion management in rangelands. Ecological Applications, v.24, n.6, p.1405-1420, fev. 2014. 